\title{
Demonstration of a Packaged Capacitive Pressure Sensor System Suitable for Jet Turbofan Engine Health Monitoring
}

\author{
Maximilian C. Scardelletti ${ }^{1}$, Jennifer L. Jordan ${ }^{1}$, Roger D. Meredith ${ }^{1}$, Kevin Harsh ${ }^{2}$, Evan Pilant ${ }^{2}$, Michael W. \\ Usrey $^{2}$, Glenn M. Beheim ${ }^{1}$, Gary W. Hunter ${ }^{1}$ and Christian A Zorman ${ }^{3}$ \\ ${ }^{1}$ NASA Glenn Reseach Center, Cleveland, OH 44135 USA \\ ${ }^{2}$ Sporian Microsystems, Lafayette, CO 80026 USA \\ ${ }^{3}$ Case Western Reserve University, Cleveland, OH 10900 USA
}

\begin{abstract}
In this paper, the development and characterization of a packaged pressure sensor system suitable for jet engine health monitoring is demonstrated. The sensing system operates from 97 to $117 \mathrm{MHz}$ over a pressure range from 0 to $350 \mathrm{psi}$ and a temperature range from 25 to $500^{\circ} \mathrm{C}$. The sensing system consists of a Clapp-type oscillator that is fabricated on an alumina substrate and is comprised of a Cree SiC MESFET, MIM capacitors, a wire-wound inductor, chip resistors and a SiCN capacitive pressure sensor. The pressure sensor is located in the LC tank circuit of the oscillator so that a change in pressure causes a change in capacitance, thus changing the resonant frequency of the sensing system. The chip resistors, wire-wound inductors and MIM capacitors have all been characterized at temperature and operational frequency, and perform with less than $5 \%$ variance in electrical performance. The measured capacitive pressure sensing system agrees very well with simulated results. The packaged pressure sensing system is specifically designed to measure the pressure on a jet turbofan engine. The packaged system can be installed by way of borescope plug adaptor fitted to a borescope port exposed to the gas path of a turbofan engine.
\end{abstract}

Keywords-component; Capacitvr pressure sensor, Clapp-type oscillator, passive components, turbofan engine

\section{INTRODUCTION}

The demonstrated utility and economic viability of microsystems technology in applications where silicon-based electronics are well suited to the environmental conditions, such as consumer electronics, healthcare, and telecommunications, has stimulated demand for comparable systems for environmentally demanding applications. Implementations of microsystems in these areas are envisioned to improve efficiency and extend operational lifetime of key components by enabling closed-loop control through the integration with control electronics. Currently, these systems lack the type of on-board control that is possible using microsystems technology due to the extreme operating conditions of system. In situations where sensor-based technologies have been implemented, the sensing part of the system is often offset from the position of interest due to inherent temperature limitations of the electronics, peripheral passive components (capacitors, inductors) and often the sensing elements themselves. Advancements in packaging technologies have not been sufficient to overcome the temperature limitations while maintaining miniaturization, which are ultimately bounded by the temperature stability of the silicon-based electronics. Approaches to locate the temperature-sensitive electronic components to cooler sections of the system have been implemented, but these approaches result in a much larger system, with significantly more wiring, larger packaging and degradation of the transduced signal due to the displacement of the signal conditioning electronics from the sensor. However, significant advances in wide-bandgap (WBG) semiconductor materials such as gallium nitride $(\mathrm{GaN})$, silicon carbide ( $\mathrm{SiC})$ and diamond (C) have enabled the development of electronic devices with maximum operating temperatures that are compatible with the high temperatures associated with the aforementioned harsh environment application. SiC electronic device technologies have advanced to the point that it is now feasible to consider the integration of electronics and microsensors into single, miniature packaged systems that can achieve accurate real-time data analysis. Notable harsh environment application areas that would significantly benefit from an infusion of microsystems technologies include: (1) oil and gas exploration/extraction, (2) automotive engine control, and (3) aerospace technologies.

\section{A. Oil and Gas Extraction applications}

The oldest and currently the largest users of high-temperature electronics are found in the downhole oil and gas industry. In downhole oil and gas drilling, the operation temperature is a function of underground depth of the well. Worldwide, the typical geothermal gradient is approximately $25^{\circ} \mathrm{C} / \mathrm{km}$ $\left(1^{\circ} \mathrm{F} / 70 \mathrm{ft}\right)$. Recently, drilling operations have seen temperatures as high as $175^{\circ} \mathrm{C}$, but declining reserves of easily accessible oil and natural gas, coupled with the advances in oil extraction technology have motivated the industry to seek deeper oil reserves [1]. These reserves are more difficult to discover and extract, necessitating the utilization of advanced sensor technologies. Drilling deeper results in significantly higher operational temperatures that can reach $300^{\circ} \mathrm{C}$, a temperature that exceeds the maximum operating limit for most integrated, Si-based microelectromechanical (MEMS). To address this issue, an active phase change cooling technique has been developed, but this approach is limited to situations where the temperatures does not exceed $250^{\circ} \mathrm{C}$ [2].

\section{B. Automotive applications}

The automotive industry is another area that will benefit from microsystems that are suitable for high temperature 
operation. For much of its history, control systems in automobiles were based on mechanical, hydraulic and vacuum based devices. However, the industry is rapidly migrating towards electromechanical and mechatronic systems. As such, the ability to locate sensors, signal conditioning, and control electronics close to the heat sources will be an essential requirement [3]. Electronic sensors designed to monitor and maintain on-engine, in-transmission, and on-wheel temperatures will have to operate between 150 and $200^{\circ} \mathrm{C}$, which can be achieved using Si-based devices. However, cylinder pressure and exhaust sensors will have to operate reliably at temperatures up to $300^{\circ} \mathrm{C}$ and $850^{\circ} \mathrm{C}$, respectively [4].

\section{Aerospcae Applications}

The aerospace industry is replete with opportunities for harsh environment microsystems. Commercial and military aircraft offer many opportunities for electronic sensing systems that can monitor and access health monitoring conditions to ensure aircraft survivability and function reliably above $300^{\circ} \mathrm{C}$. Electronic systems that can detect variable changes in emissions, temperature, blade tip clearance and pressure are being developed for aircraft engines and must be able to sustain the harsh conditions, such as vibration, pressure and temperature [5]. Such systems developed for this purpose at NASA include emissions, temperature, blade tip clearance and pressure [5-8].

The need for high temperature microsystems is not limited to aeronautical applications. The Venus Exploration Analysis Group (VEXAG) within NASA is assessing the feasibility of sending probes and landers to Venus to determine the atmospheric formation, evolution, and climate history of the planet [8]. Such a mission will expose the probes to atmospheric conditions with temperatures as high as $480^{\circ} \mathrm{C}$. Size and weight restrictions prohibit the use of active cooling, distributed components and conventional packaging approaches to shield Si-based electronics from these prohibitively high temperatures. At this point, the leading approach is to utilize electronics, sensors and peripheral components that are fabricated from temperature tolerant materials, with $\mathrm{SiC}$ as the leading candidate material.

\section{Sensor Develeopment for Aerospcae Applications}

This paper will discuss the development of a packaged capacitive pressure sensor system designed specifically to measure pressures in a turbofan engine. The sensor system integrates high temperature SiC-based MESFET electronics and a MEMS-based silicon carbide nitride (SiCN) capacitive pressure sensor into a Clapp-type oscillator circuit that is fabricated on an alumina substrate. The sensor system is packaged in a custom fabricated stainless steel metal housing that is able to pass temperature, pressure and vibration tests at $500^{\circ} \mathrm{C}, 300$ psi and $10.6 \mathrm{G}_{\mathrm{rms}}$, respectively.

The packaged pressure sensor system can be installed by way of a borescope plug adaptor fitted to a borescope port to expose the sensor to the gas path of the gas turbofan engine. Potential tests that can be performed using this system include normal engine operation with adjustments to the fan speed both in steady-state and transient.

\section{PASSIVE COMPONENT CHARACTERIZATION}

The pressure sensor system developed here is based on a Clapp-type oscillator that is composed of resistors, inductors, capacitors, a sensor and a transistor. Even though the sensor and active device are considered critical for this system, the resistors, inductors and capacitors are of equal importance especially because these components also must perform reliably at the same temperatures. Thus, it is imperative that each of the passive components do not compromise the performance of the pressure sensor system over the operational temperature range. Otherwise, the performance of the oscillator can change considerably, if not fail all together. To demonstrate the feasibility of these components, they were individually characterized over the operational temperature range of the pressure system.

\section{A. MIM Capacitors}

The Clapp-type oscillator used in this sensor system requires two Metal-Insulating-Metal (MIM) capacitors with a titanate insulator and a titanium/platinum/gold metallization layer on both sides. The titanate insulator has a dielectric constant of 40 and a thickness of $1.016 \mathrm{~mm}$. The MIM capacitors have square areas of 4 and $12.25 \mathrm{~mm}^{2}$, which result in capacitances of approximately 14 and $41 \mathrm{pF}$, respectively. The MIM capacitors as well as the inductors and resistors were characterized on CoorsTek 996 Alumina Superstrate and $\mathrm{Ti} / \mathrm{Au}$ metallization patterns were used to facilitate the measurement. To verify performance of the capacitors at high temperatures and at the operational frequency range, the capacitors were characterized using three methods. In the first method, the S-parameters were recorded with an network analyzer from room temperature $\left(25^{\circ} \mathrm{C}\right)$ to $400^{\circ} \mathrm{C}$ in steps of $50^{\circ} \mathrm{C}$ over a frequency range of 10 to $200 \mathrm{MHz}$. To facilitate the measurement a high temperature probe station, shown Fig.1, was used. The probe station consists of a ceramic heater on a chuck made of a high temperature insulating tile, a thermocouple and power source. A LabView program is used to control the temperature settings. 


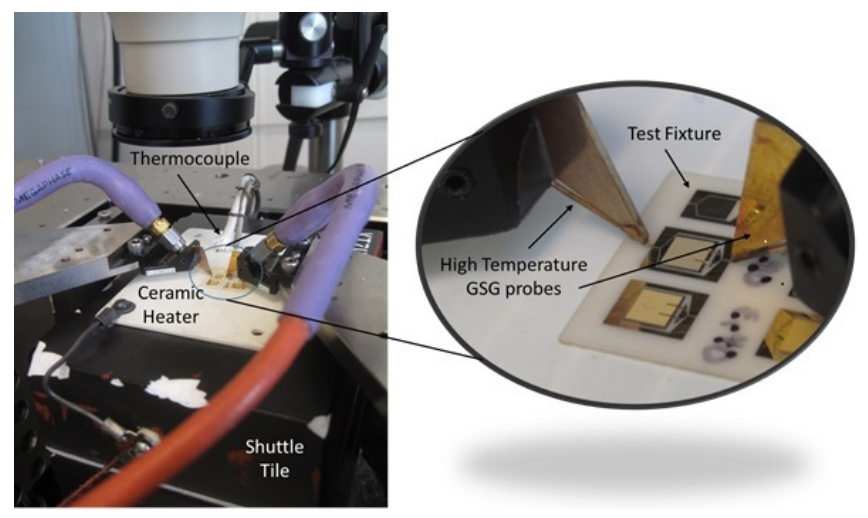

Figure1. High temperature probe station.

Ground-signal-ground (GSG) high temperature probes with a $150 \mu \mathrm{m}$ pitch were calibrated with a short-open-loadthru (SOLT) calibration substrate to ensure accuracy to the probe tips. The calibration was only performed at room temperature, due to the temperature dependence of the calibration substrate The MIM capacitors were epoxied to test fixtures on an alumina substrate, which can be seen in the inset of Fig. 1. The measured S-parameters of the $41 \mathrm{pF}$ MIM capacitor at 25 and $400^{\circ} \mathrm{C}$, shown in Fig. 2, are independent of temperature.

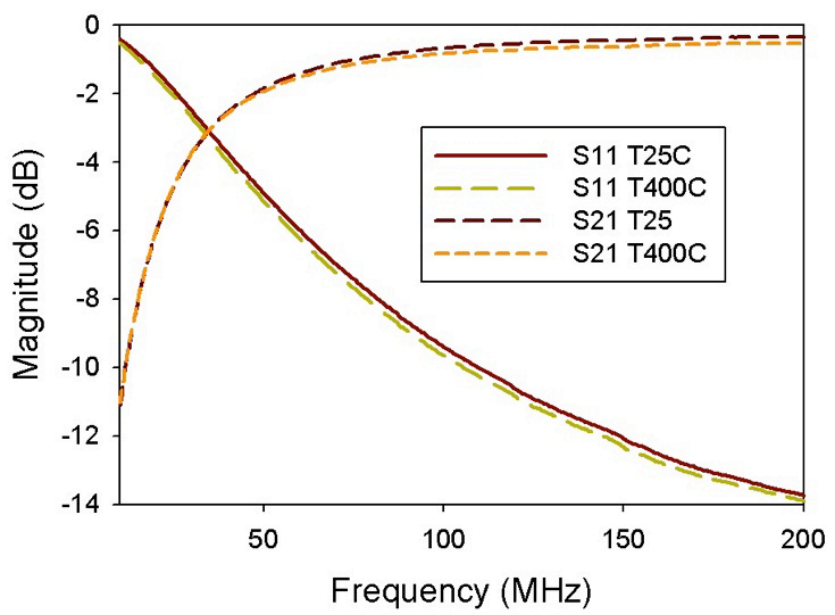

Figure 2. Measured S-parameters of the $41 \mathrm{pF}$ MIM capacitor at 25 and $400^{\circ} \mathrm{C}$.

The lumped element circuit model, shown in Fig. 3, was optimized against the measured S-parameters in Keysight's Advanced Design System (ADS) software suite. The gradient optimizer is used in all the simulations. The lumped element model consists of a series capacitance, $\mathrm{C}_{\mathrm{S}}$, parasitic capacitances, $\mathrm{C}_{1}$ and $\mathrm{C}_{2}$, series resistance, $\mathrm{R}_{\mathrm{s}}$, and series inductance, Ls. To demonstrate the accuracy of the optimization method, the S-parameters of the $41 \mathrm{pF}$ MIM capacitor at $400^{\circ} \mathrm{C}$ are optimized against the capacitor equivalent circuit model and the results are shown in Fig. 4. The measured and optimized traces for $S_{11}$ and $S_{21}$ are virtually indistinguishable from one another, indicating the validity of the lumped element

All of the component values acquired from the optimization method for both the 14 and $41 \mathrm{pF}$ MIM capacitors from 25 to $400^{\circ} \mathrm{C}$ are listed in Tables 1 and 2, respectively. Note that this method results in frequency independent component values.

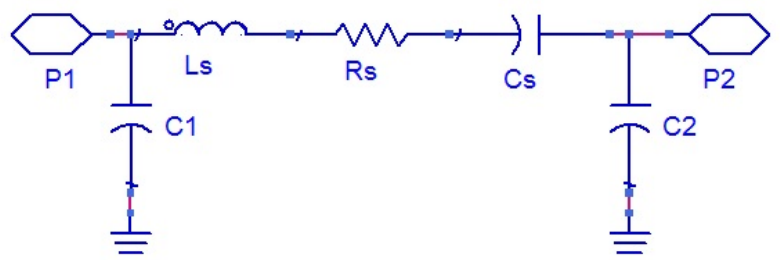

Figure 3. Equivalent circuit model for MIM capacitors.

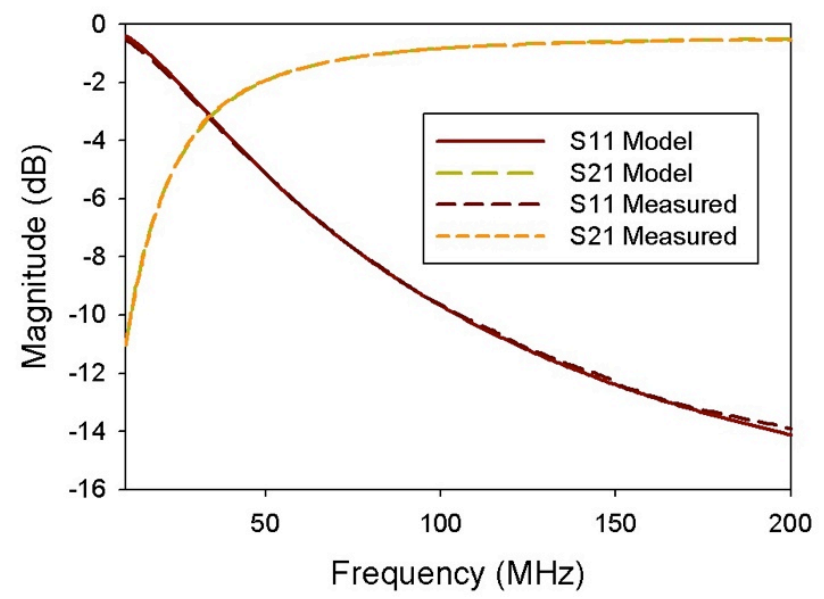

Figure 4. Comparison between measured and optimized modeled data of $14 \mathrm{pF}$ MIM capacitor at $400^{\circ} \mathrm{C}$.

Table 1. Circuit model values for $14 \mathrm{pF}$ MIM capacitor.

\begin{tabular}{|c|c|c|c|c|c|}
\hline Temp $\left({ }^{\circ} \mathbf{C}\right)$ & Cs (pF) & Rs $(\boldsymbol{\Omega})$ & Ls $(\mathbf{n H})$ & $\mathbf{C} \mathbf{( p F )}$ & $\mathbf{C} \mathbf{( p F )}$ \\
\hline $\mathbf{2 5}$ & 13.85 & 1.934 & 2.114 & 0.437 & 1.204 \\
\hline $\mathbf{5 0}$ & 13.87 & 2.144 & 2.145 & 0.436 & 1.207 \\
\hline $\mathbf{1 0 0}$ & 13.911 & 2.487 & 2.19 & 0.435 & 1.219 \\
\hline $\mathbf{1 5 0}$ & 13.931 & 2.623 & 2.23 & 0.439 & 1.228 \\
\hline $\mathbf{2 0 0}$ & 13.972 & 3.189 & 2.314 & 0.449 & 1.239 \\
\hline $\mathbf{2 5 0}$ & 14.003 & 3.371 & 2.311 & 0.452 & 1.244 \\
\hline $\mathbf{3 0 0}$ & 14.039 & 3.796 & 2.391 & 0.454 & 1.253 \\
\hline $\mathbf{3 5 0}$ & 14.084 & 4.14 & 2.406 & 0.456 & 1.258 \\
\hline $\mathbf{4 0 0}$ & 14.132 & 4.631 & 2.468 & 0.44 & 1.261 \\
\hline
\end{tabular}


Table 2. Circuit model values for $41 \mathrm{pF}$ MIM capacitor.

\begin{tabular}{|c|c|c|c|c|c|}
\hline Temp $\left({ }^{\circ} \mathbf{C}\right)$ & Cs (pF) & Rs $(\mathbf{\Omega})$ & Ls $(\mathbf{n H})$ & $\mathbf{C 1}(\mathbf{p F})$ & $\mathbf{C 2}(\mathbf{p F})$ \\
\hline $\mathbf{2 5}$ & 42.804 & 1.778 & 2.645 & 0.352 & 1.863 \\
\hline $\mathbf{5 0}$ & 42.865 & 1.916 & 2.669 & 0.346 & 1.874 \\
\hline $\mathbf{1 0 0}$ & 42.993 & 2.245 & 2.716 & 0.344 & 1.893 \\
\hline $\mathbf{1 5 0}$ & 43.082 & 2.482 & 2.756 & 0.352 & 1.909 \\
\hline $\mathbf{2 0 0}$ & 43.179 & 2.834 & 2.807 & 0.357 & 1.919 \\
\hline $\mathbf{2 5 0}$ & 43.28 & 3.112 & 2.847 & 0.364 & 1.924 \\
\hline $\mathbf{3 0 0}$ & 43.368 & 3.325 & 2.88 & 0.367 & 1.932 \\
\hline $\mathbf{3 5 0}$ & 43.509 & 3.668 & 2.928 & 0.363 & 1.939 \\
\hline $\mathbf{4 0 0}$ & 43.641 & 4.064 & 2.965 & 0.357 & 1.943 \\
\hline
\end{tabular}

The modeled S-parameter data shows that the values of the two MIM capacitors changes by approximately $2 \%$ from 25 to $400^{\circ} \mathrm{C}$. Rs increases by approximately $2.5 \Omega$, which may be due the inability to calibrate out the additional loss of the probes as they approach $400^{\circ} \mathrm{C}$. The shunt parasitic capacitances, $\mathrm{C}_{1}$ and $\mathrm{C}_{2}$, and the parasitic series inductance, Ls, are negligible for both the 14 and the $41 \mathrm{pF}$ MIM capacitors.

The second method used to characterize the MIM capacitors involved a semiconductor device analyzer (SDA) and high temperature probe station. The GSG probes were replaced with DC needle probes, enabling the temperature range to be extended to $500^{\circ} \mathrm{C}$. The measurements were recorded from 25 to $500^{\circ} \mathrm{C}$ in steps of $50^{\circ} \mathrm{C}$. A calibration that consisted of a phase compensation to account for the port extension and an open and short was performed to set the reference plane at the probe tips. The measurements were taken at 9.950, 9.975, 1, 1.025 and $1.050 \mathrm{MHz}$ and the average value was recorded. The results are shown in Fig.5.

The 14 and $41 \mathrm{pF}$ MIM capacitors change by approximately 2 - $3 \%$ from 25 to $400^{\circ} \mathrm{C}$ and up to $5 \%$ from $400^{\circ} \mathrm{C}$ to $500^{\circ} \mathrm{C}$. Furthermore, the conductance was measured and found to be negligible up to $400^{\circ} \mathrm{C}$ and then rose to no more than $10 \mu \mathrm{S}$ for both the 14 and $41 \mathrm{pF}$ capacitors at $500^{\circ} \mathrm{C}$. It is not evident if the degradation in electrical performance was due to the temperature dependence of the material or probe contacts beginning to degrade due to the extreme environment.

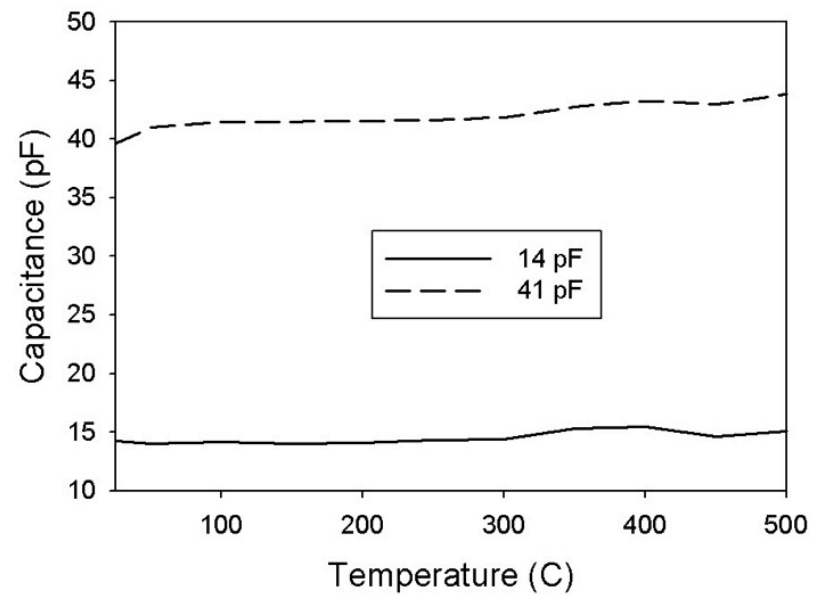

Figure 5. MIM capacitors measured from 25 to $500^{\circ} \mathrm{C}$ at 1 $\mathrm{MHz}$ on the SDA.

Lastly, the MIM capacitors were measured using a fourpoint probing technique on an impedance analyzer from 40 $\mathrm{Hz}$ to $110 \mathrm{MHz}$ at room temperature to determine if they are able to operate at the desired frequency range. It is vital to ensure that the passive components do not have a selfresonant frequency (SRF) near the operating frequency range of the sensing system. A calibration was performed, consisting of a phase compensation to account for the port extension, and an open, short and load to set the reference plane at the probe tips. The measured data is shown in Fig. 6.

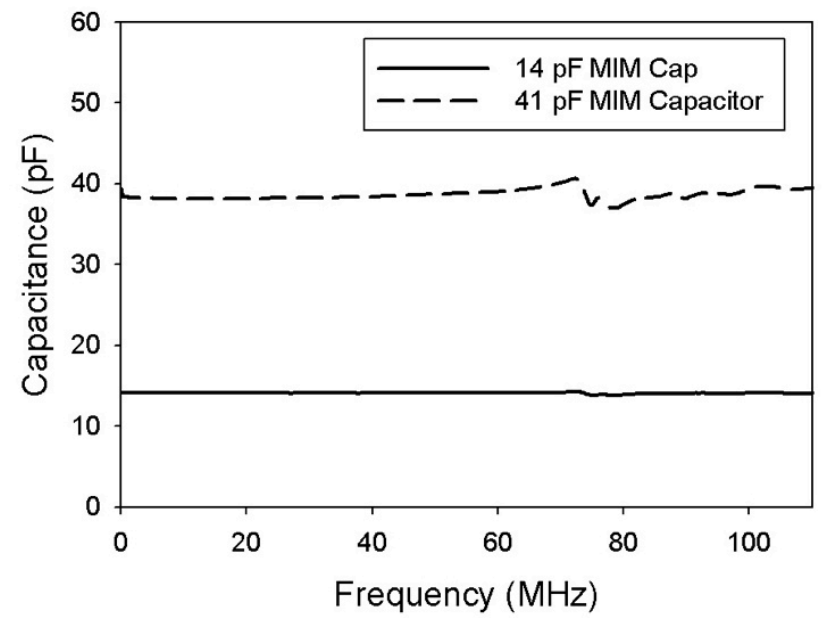

Figure 6. MIM capacitors measured from 0.04 to $110 \mathrm{MHz}$.

The values of the 14 and $44 \mathrm{pF}$ capacitors are constant across the measured frequency range, varying by less than $2 \%$. The fluctuation in the measured data that occurs at roughly 75 to $90 \mathrm{MHz}$ is due to the calibration routine not properly working at that frequency range, and as a result the data obtained in this frequency range is inaccurate. However, 
the calibration does recover around $90 \mathrm{MHz}$ and is good up to $110 \mathrm{MHz}$ indicating that there is no SRF near the operational frequency range of the sensing system.

\section{B. Wirewound Chip Inductors}

The Clapp-type oscillator design also requires one $390 \mathrm{nH}$ inductor, located in the LC resonate tank circuit of the device. This inductor is in series with the capacitive pressure sensor, which dictates the resonant frequency of the sensing system. The inductor used in this sensing system is a Johanson $390 \mathrm{nH}$ wirewound inductor, with dimensions of 2 $\mathrm{x} 1.2 \times 1.2 \mathrm{~mm}^{3}$ ( 1 x w x t). As with the MIM capacitors, three methods are used to validate the response of the inductor over the desired frequency and temperature ranges.

The S-parameters of the $390 \mathrm{nH}$ inductor were measured in the same manner on the PNA as the capacitors. The circuit model used is shown in Fig. 7. The model consists of a series inductor and resistor and two capacitors in shunt.

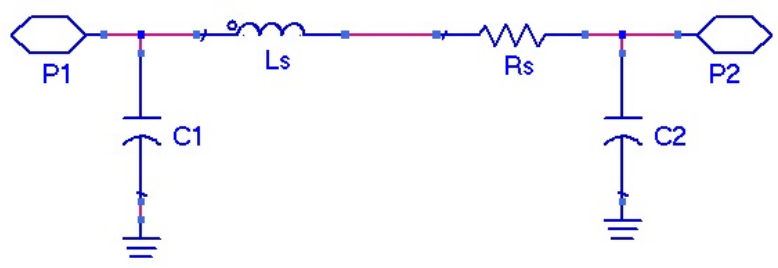

Figure 7. Equivalent circuit model for wirewound inductor.

The S-parameters were optimized against the circuit model in ADS and the gradient optimizer is used in all the simulations. The optimization method results were just as accurate as with the MIM capacitors resulting in close agreement between the $S_{11}$ and $S_{21}$ measured and optimized modeled traces. The values for all the circuit model components are shown in Table 3. Just as with the capacitor model components, this method results in frequency independent component values.

Table 3. Circuit model values for 390 wirewound inductor.

\begin{tabular}{|c|c|c|c|c|}
\hline Temp $\left({ }^{\circ} \mathbf{C}\right)$ & Ls $(\mathbf{n H})$ & Rs $(\boldsymbol{\Omega})$ & $\mathbf{C 1}(\mathbf{p F})$ & $\mathbf{C 2}(\mathbf{p F})$ \\
\hline $\mathbf{2 5}$ & 397.887 & 4.02 & 0.531 & 0.593 \\
\hline $\mathbf{5 0}$ & 398.515 & 4.426 & 0.534 & 0.6 \\
\hline $\mathbf{1 0 0}$ & 399.779 & 5.015 & 0.538 & 0.605 \\
\hline $\mathbf{1 5 0}$ & 400.932 & 5.633 & 0.55 & 0.616 \\
\hline $\mathbf{2 0 0}$ & 401.975 & 6.195 & 0.553 & 0.623 \\
\hline $\mathbf{2 5 0}$ & 401.381 & 6.9 & 0.561 & 0.627 \\
\hline $\mathbf{3 0 0}$ & 404.637 & 7.658 & 0.568 & 0.625 \\
\hline $\mathbf{3 5 0}$ & 405.295 & 9.281 & 0.562 & 0.629 \\
\hline $\mathbf{4 0 0}$ & 408.321 & 12.289 & 0.579 & 0.634 \\
\hline
\end{tabular}

The value of the inductor, Ls, increased by 3\% from 25 to $400^{\circ} \mathrm{C}$, demonstrating that the inductor is viable through this temperature range. However, the series resistance, $R_{S}$, increases from 4.02 to $6.195 \Omega$ from 25 to $200^{\circ} \mathrm{C}$, which is an increase of $53 \%$. Furthermore, $\mathrm{R}_{\mathrm{S}}$ increased by nearly $100 \%$ from 200 to $400^{\circ} \mathrm{C}$, thus indicating that the material composition of the inductor is beginning to deteriorate and degrade its electrical performance. Shortly after $400^{\circ} \mathrm{C}$, the inductor fails, and if taken up to $500^{\circ} \mathrm{C}$, the physical damage is irreversible.

The inductors were also characterized on the SDA. The inductors were only characterized through $400^{\circ} \mathrm{C}$ due to the realization that the wirewound inductors would begin to fail above this temperature. The results are shown in Fig. 8. The inductance of the wirewound inductor changes from 408 to $417 \mathrm{nH}$ from 25 to $400^{\circ} \mathrm{C}$, roughly $2.5 \%$, over this temperature range. The series resistance was also characterized from 25 to $400^{\circ} \mathrm{C}$ at $1 \mathrm{MHz}$. Just as with the inductor characterization with the optimization modeling, the series parasitic resistance is fairly linear up to $300^{\circ} \mathrm{C}$ and then starts increase rapidly to $400^{\circ} \mathrm{C}$, indicating that the component is probably reaching its maximum operating temperature.

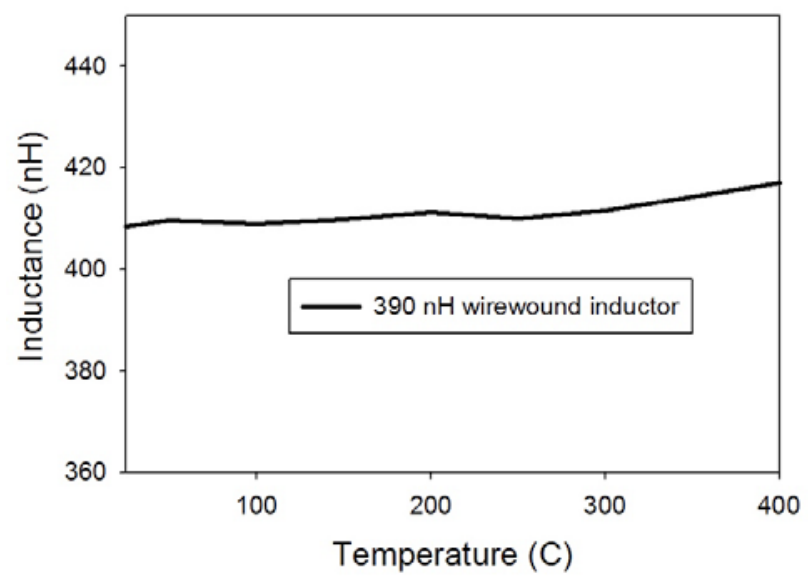

Figure 8. Wirewound inductor measured from 25 to $400^{\circ} \mathrm{C}$ at $1 \mathrm{MHz}$ on the SDA. 


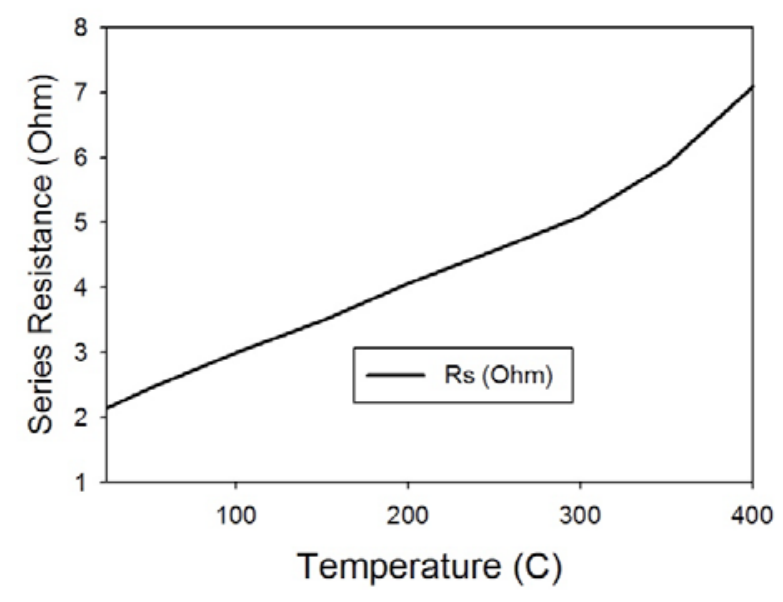

Figure 9. Series parasitic resistance characterized from 25 to $400^{\circ} \mathrm{C}$ at $1 \mathrm{MHz}$.

Finally, to determine the inductor performance over the operational frequency range of the sensing system, the inductor was characterized on the impedance analyzer from 40 to $110 \mathrm{MHz}$ at room temperature, and the results are shown in Fig. 10. Again, at approximately 75 to $90 \mathrm{MHz}$ the measurement is inaccurate due to an error in the calibration routine. However, from 90 to $110 \mathrm{MHz}$ the calibration recovered and from the data trace it is evident that the inductor is operational over the design frequency range from 97 to $117 \mathrm{MHz}$.

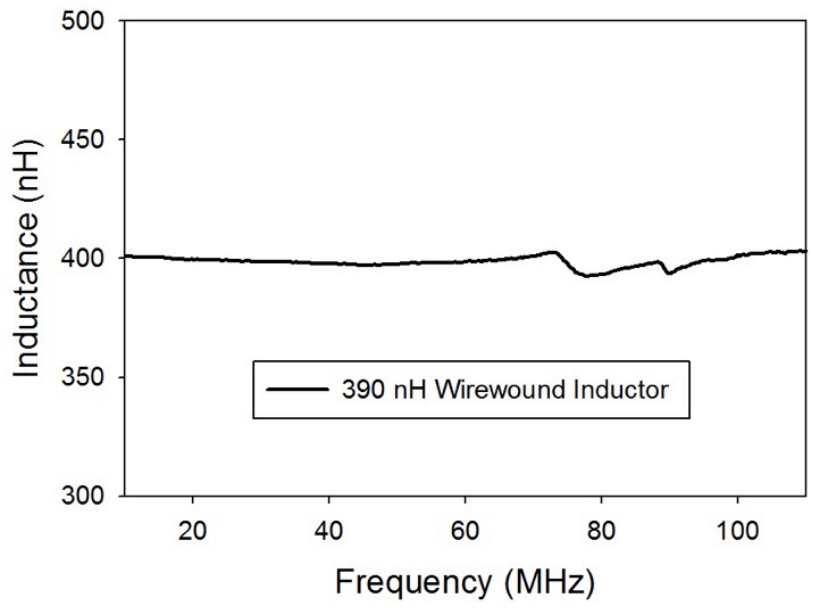

Figure 10. Series parasitic resistance of the $390 \mathrm{nH}$ wirewound inductor form 0.04 to $110 \mathrm{MHz}$ at room temperature.

\section{Thick Film Chip Resistors}

A $10 \mathrm{k} \Omega$ is resistor is used in the DC bias circuit of the gate side of the SiC Cree MESFET to simplify and reduce the overall size, while maintaining the ability to prevent RF from leaking back into the gate power supply. Since the gate of the
FET requires no current, only RF blocking is required and the $10 \mathrm{k} \Omega$ resistor is sufficiently large. The $10 \mathrm{k} \Omega$ thick film chip resistor is from MiniSytems Inc. with dimensions of $1.118 \mathrm{x}$ $0.559 \times 0.330 \mathrm{~mm}^{3}(\mathrm{l} \mathrm{x} \mathrm{w} \mathrm{x} \mathrm{t})$. The resistor has a voltage and power rating of $40 \mathrm{~V}$ and $0.04 \mathrm{~W}$, respectively.

The resistance equivalent circuit model used to optimize against the measured S-parameters of the resistor is the same circuit model used for the wirewound inductor shown in Fig. 7. The S-parameters were optimized from 10 to $200 \mathrm{MHz}$, and the gradient optimizer was used for all simulation. The results in Table 4 show that the change in resistance from 25 to $400^{\circ} \mathrm{C}$ is negligible. Also, the parasitics $\mathrm{Ls}_{\mathrm{s}}, \mathrm{C}_{1}$, and $\mathrm{C}_{2}$ are negligible as well.

Table 4. Circuit model values for $10 \mathrm{k} \Omega$ chip resistor.

\begin{tabular}{|c|c|c|c|c|}
\hline Temp $\left({ }^{\circ} \mathbf{C}\right)$ & Rs (k) & Ls $(\mathbf{n H})$ & $\mathbf{C} \mathbf{( p F )}$ & $\mathbf{C 2}(\mathbf{p F})$ \\
\hline $\mathbf{2 5}$ & 10.13 & $1.00 \mathrm{E}-05$ & 0.578 & 0.556 \\
\hline $\mathbf{5 0}$ & 10.14 & $1.00 \mathrm{E}-05$ & 0.578 & 0.559 \\
\hline $\mathbf{1 0 0}$ & 10.07 & $1.00 \mathrm{E}-05$ & 0.582 & 0.561 \\
\hline $\mathbf{1 5 0}$ & 10.06 & $1.00 \mathrm{E}-05$ & 0.588 & 0.569 \\
\hline $\mathbf{2 0 0}$ & 10.01 & $1.00 \mathrm{E}-05$ & 0.597 & 0.574 \\
\hline $\mathbf{2 5 0}$ & 10.08 & $1.00 \mathrm{E}-05$ & 0.599 & 0.578 \\
\hline $\mathbf{3 0 0}$ & 10.08 & $1.00 \mathrm{E}-05$ & 0.606 & 0.579 \\
\hline $\mathbf{3 5 0}$ & 10.12 & $1.00 \mathrm{E}-05$ & 0.612 & 0.581 \\
\hline $\mathbf{4 0 0}$ & 10.12 & $1.00 \mathrm{E}-05$ & 0.596 & 0.579 \\
\hline
\end{tabular}

Next, the resistor was characterized from 25 to $500^{\circ} \mathrm{C}$ with a $6 \frac{1}{2}$ digit multimeter, DC needle probes, and the high temperature probe station. The results are shown in Fig. 10. At $25^{\circ} \mathrm{C}$, the resistance is $10.1 \mathrm{k} \Omega$ and at $500^{\circ} \mathrm{C}$ the resistance is $10.7 \mathrm{k} \Omega$, which is a $6 \%$ increase in resistance over the entire temperature range. Furthermore when the resistor is cooled to room temperature the resistance goes back to its original value of $10.1 \mathrm{k} \Omega$ indicating that this resistor is well suited for circuits and systems that operate up to $500^{\circ} \mathrm{C}$.

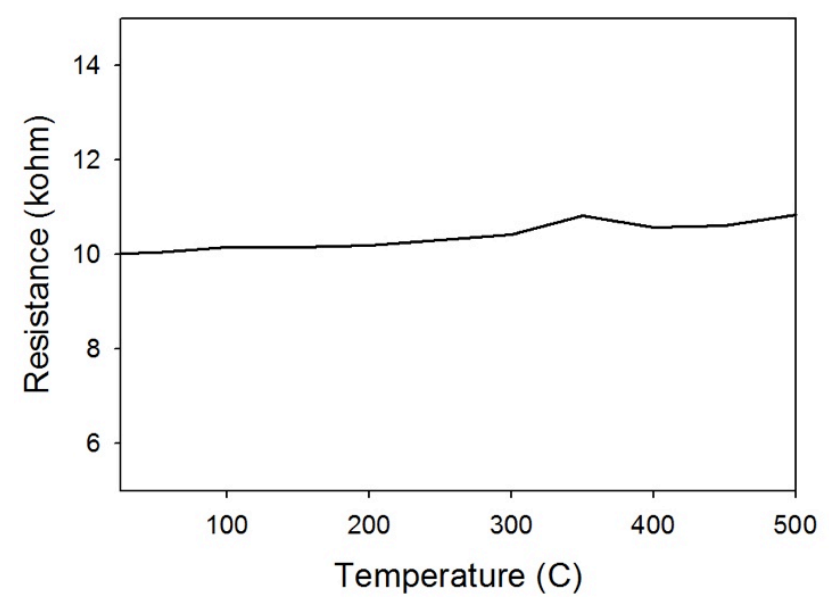

Figure $10.10 \mathrm{k} \Omega$ resistor response from 25 to $500^{\circ} \mathrm{C}$. 


\section{CAPACITIVE PRESSURE SENSOR}

The micro-electromechanical systems (MEMS) capacitive pressure sensor, developed by Sporian Microsystems, is shown in Fig. 11. The sensor is fabricated from SiCN which is a high temperature material synthesized by thermal decomposition of polymeric precursors that possesses excellent mechanical properties, tunable electric properties and superior oxidation/corrosion resistance at temperatures up to $1600^{\circ} \mathrm{C}[10,11,12,13]$. The sensor and gold metal feed lines are fabricated on a high purity alumina substrate. One electrode of the capacitive sensor is fabricated on the deflecting chamber membrane that forms a sealed cavity, and the second electrode is on the fixed alumina substrate. The sealed cavity is flip-chip bonded onto the alumina substrate with gold contacts such that the two electrodes form a parallel plate capacitor. Thus, as pressure increases the membrane is flexed up into the sealed cavity causing the capacitance of the pressure sensor to decrease.

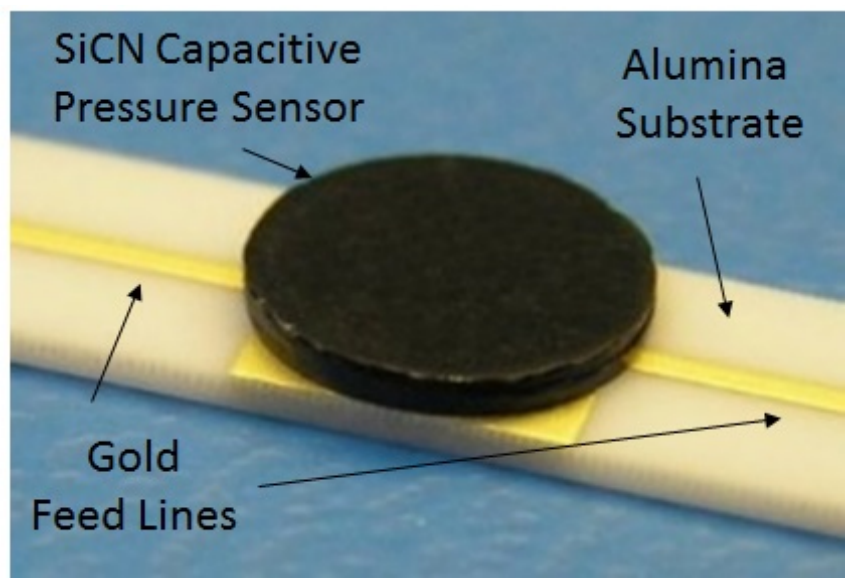

Figure 11. Sporian Microsystem capacitive pressure sensor.

The pressure sensor was characterized with the SDA, as was used for the passive components, and a high temperature/pressure chamber (HTPC), shown in Fig. 12. The HTPC is capable of operating up to $500^{\circ} \mathrm{C}$ and pressures up to 100 psi. The chamber is equipped with a $125 \mathrm{~mm}$ diameter quartz sight glass for signal transmission, a ceramic heater, and thermocouples located throughout the chamber to ensure accurate temperature readings. The SDA was calibrated to the leads of the pressure sensor inside the HTPC at room temperature to remove the effects of the chamber and cabling. The pressure sensor capacitance was measured at $1 \mathrm{MHz}$ from 0 to $100 \mathrm{psi}$ at $25^{\circ} \mathrm{C}$, and the results are shown in Fig. 13. Over the pressure range, the capacitance changes linearly from 3.84 to $3.3 \mathrm{pF}$, which is a $\Delta \mathrm{C}$ of $0.54 \mathrm{pF}$. Furthermore, the pressure sensor maintains a linear response from room temperature to $500^{\circ} \mathrm{C}$, over the 100 psi pressure range [8].
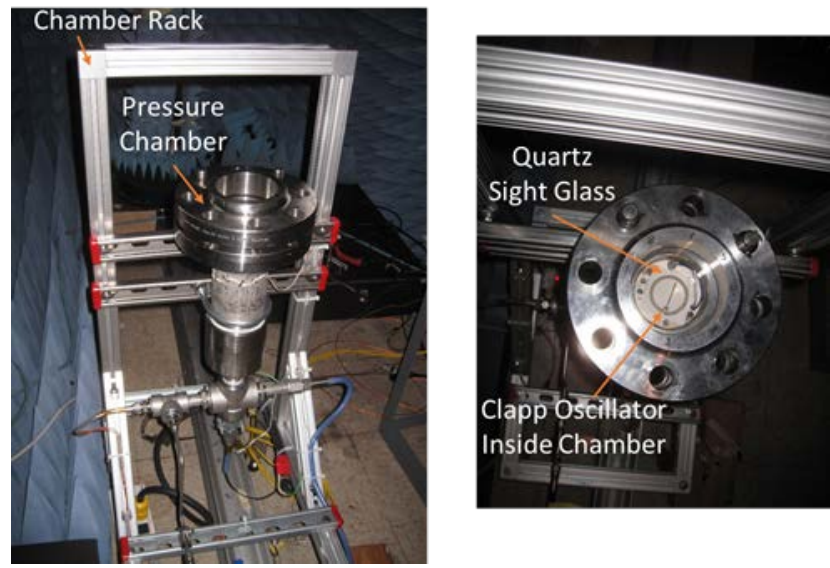

Figure 12. High temperature pressure chamber.

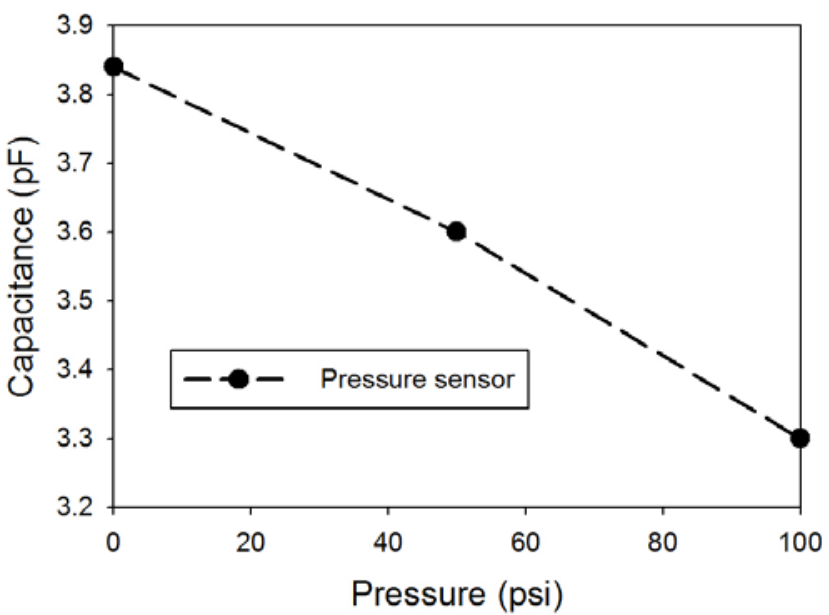

Figure 13. Capacitive pressure sensor pressure vs. capacitance.

The Sporian pressure sensor was also characterized from $40 \mathrm{~Hz}$ to $110 \mathrm{MHz}$ at atmospheric pressure with the impedance analyzer, and the results are shown in Fig. 14. The response indicates that the pressure sensor capacitance at room temperature does not vary significantly and there is no indication of the SRF over the operational frequency of the pressure sensor system. The roughness in the trace is mainly due to the calibration. 


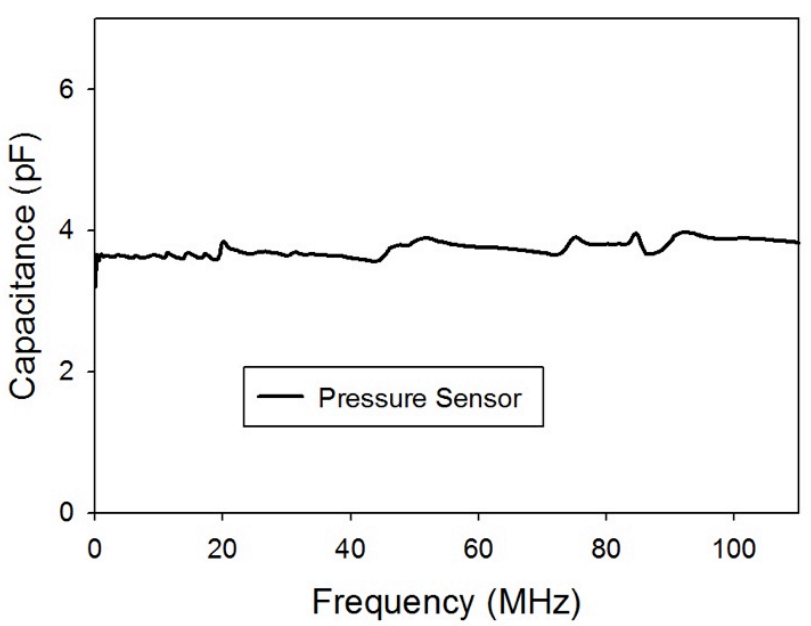

Figure 14. Sporian capacitive pressure sensor response from $40 \mathrm{~Hz}$ to $110 \mathrm{MHz}$ at atmospheric pressure.

\section{PRESSURE SENSOR SYSTEM DESIGN}

The sensor system, shown schematically in Fig. 15, consists of a Clapp-type oscillator with a MEMS capacitive pressure sensor located in the LC tank circuit of the device. The Clapp-type oscillator design in this system requires one inductor $\left(\mathrm{L}_{\mathrm{T}}\right)$, three capacitors $\left(\mathrm{C}_{\mathrm{T}}, \mathrm{C}_{1}\right.$ and $\left.\mathrm{C}_{2}\right)$ and one MESFET. DC bias circuitry is added at the gate and drain inputs and consist of a series $10 \mathrm{k} \Omega$ resistor on the gate and two $90 \mathrm{pF}$ MIM capacitors in shunt and a $390 \mathrm{nH}$ wirewound inductor on the drain, as seen in Fig, 15. The Clapp-type oscillator design was selected because it requires significantly fewer passive components than other oscillator designs. Under conditions characteristic of a gas turbine engine (i.e., high temperature and high vibration), fewer environmentally sensitive components reduces the probability of failure.

Moreover, because it requires fewer components, the Clapp-type design can be made into systems of smaller form factor, enabling deployment in confined locations. Another advantage of the Clapp oscillator design is that the inductor $\left(\mathrm{L}_{\mathrm{T}}\right)$ and capacitive pressure sensor $\left(\mathrm{C}_{\mathrm{T}}\right)$ are in series, where $\mathrm{C}_{\mathrm{T}}$ is used to set the operational frequency range, while $\mathrm{C}_{1}$ and $\mathrm{C}_{2}$ is used to control the gain conditions. This arrangement improves the frequency stability of the circuit, making the Clapp oscillator a better option than other oscillator designs.

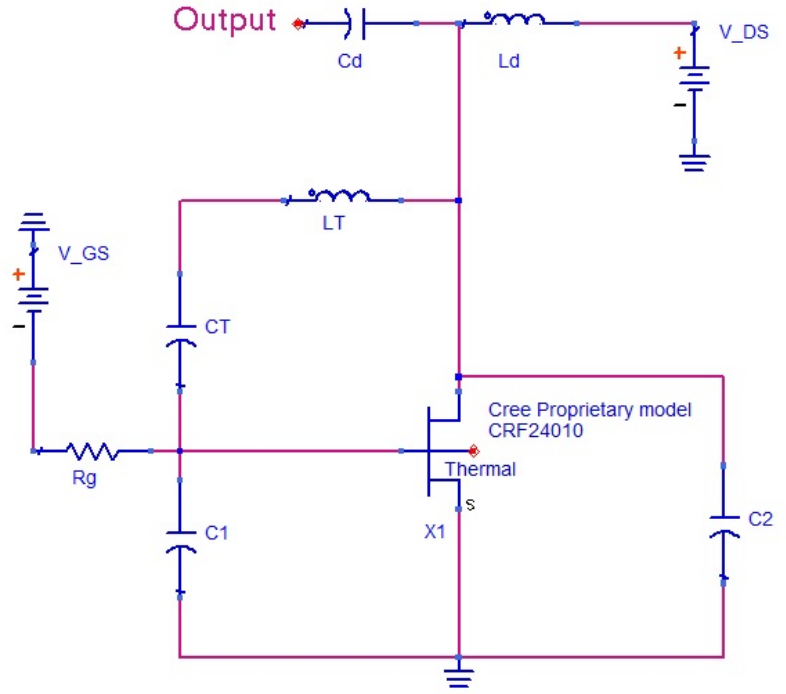

Figure 15. Circuit schematic of Clapp-type oscillator-based pressure sensor system.

The pressure sensor system was designed with Keysight's ADS circuit simulator. A model of the Cree SiC MESFET is used in all simulations. The model was developed by Cree and Agilent (now Keysight) and accurately represents the transistor characteristics. The values for $\mathrm{C}_{\mathrm{T}}, \mathrm{L}_{\mathrm{T}}, \mathrm{C}_{1}, \mathrm{C}_{2}, \mathrm{R}_{\mathrm{G}}$, $\mathrm{L}_{\mathrm{D}}$ and $\mathrm{C}_{\mathrm{D}}$ are $3.84 \mathrm{pF}, 780 \mathrm{nH}, 14 \mathrm{pF}, 41 \mathrm{pF}, 10 \mathrm{k} \Omega, 390 \mathrm{nH}$ and $188 \mathrm{pF}$, respectively. The two main criteria for an oscillator to achieve oscillation at the operating frequency are (1) the phase of the device is around $0^{\circ}$ and (2) the loop gain is close to unity [14]. The simulated S-parameters are shown in Fig. 16 and 17. The S-parameters show that the phase is $0^{\circ}$ and the closed-loop gain is greater than unity at an operating frequency of $97 \mathrm{MHz}$. To simulate the response of the pressure sensor system, the capacitance of the sensor, $\mathrm{C}_{\mathrm{T}}$, is decreased and therefore the resonant frequency of the system increases. As the pressure increases from 0 to $100 \mathrm{psi}$, the frequency of the pressure sensor system increases from 97 to $103 \mathrm{MHz}$, which is an increase of $6 \%$. To capture this response, a harmonic balance simulation was performed and the results are shown in Fig. 18. The results indicate that when the capacitive pressure sensor is $3.84 \mathrm{pF}$ (0 psi), $3.6 \mathrm{pF}$ (50 psi) and $3.3 \mathrm{pF}(100 \mathrm{psi})$, the resonant frequency is approximately $96.7 \mathrm{MHz}, 99.2 \mathrm{MHz}$ and $102.8 \mathrm{MHz}$, respectively. 


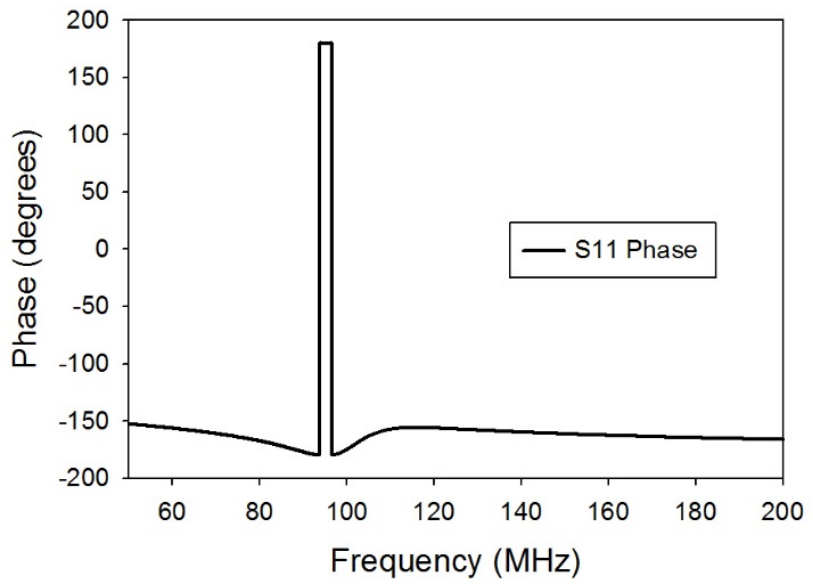

Figure 16 . Phase of sensor system is $0^{\circ}$ at operating frequency.

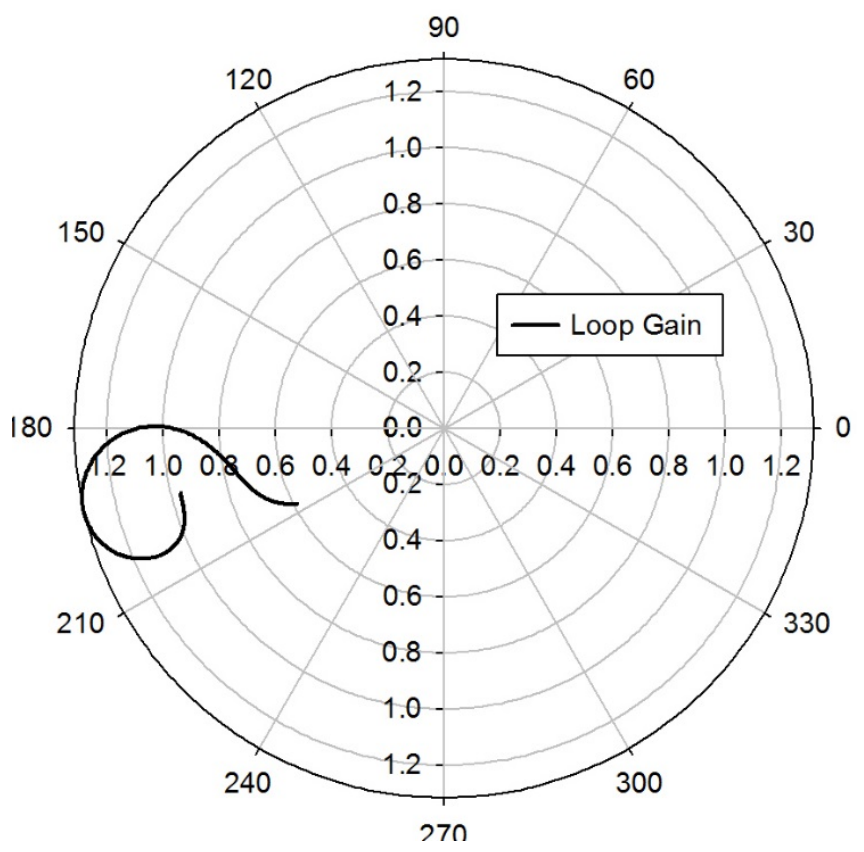

Figure 17. Closed loop gain of sensor system greater than unity at operating frequency.

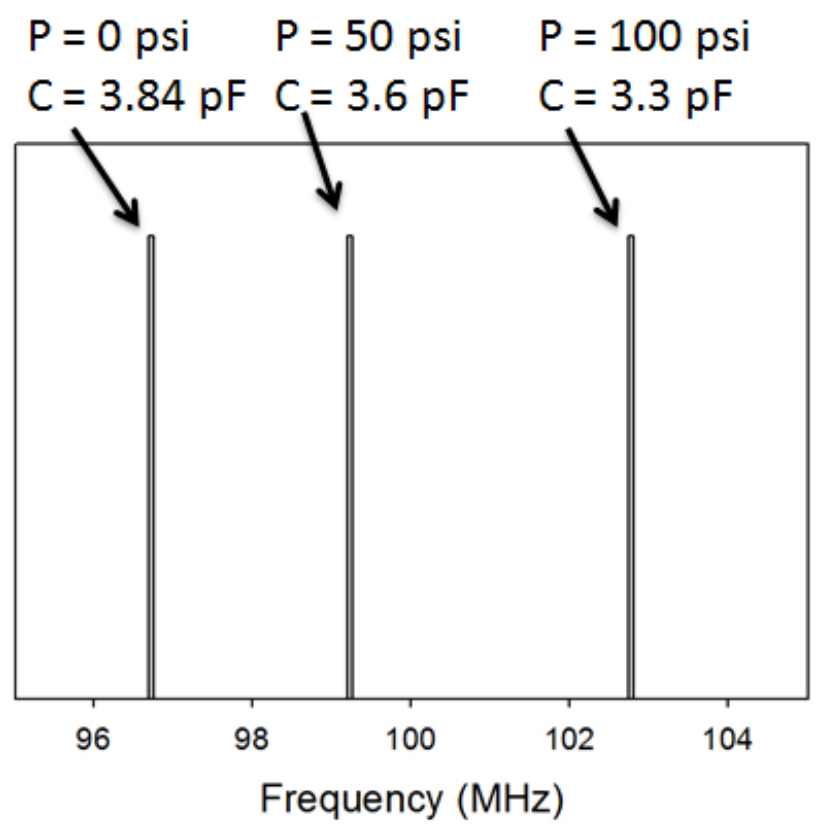

Figure 18. Pressure sensor system resonate frequency changes as the pressure sensor capacitance changes due to pressure.

\section{FABRICATION, PACKAGING AND VALIDATION}

The sensor system was fabricated on an alumina substrate and is shown in Figs. 19 and 20. Fig. 20 also shows the stainless steel metal packaging fixture. The substrate is $3.5 \mathrm{~mm}$ wide by $5 \mathrm{~mm}$ long by $500 \mu \mathrm{m}$ thick. The stainless steel package is $150 \mathrm{~mm}$ by $30 \mathrm{~mm}$ as seen in the figure. The cylindrical sleeve that fits over the pressure sensor circuit has an inner diameter of $4 \mathrm{~mm}$. The metallization traces on the alumina is composed of a titanium/gold layer, and uses gold wire bonds to facilitate continuity.

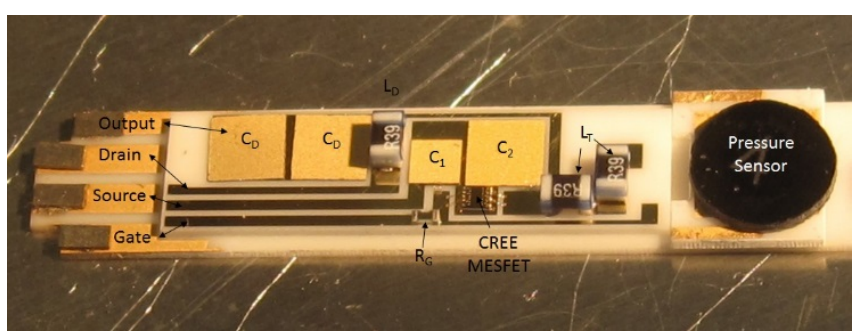

Figure 19. Assembled pressure sensor system on alumina substrate. 


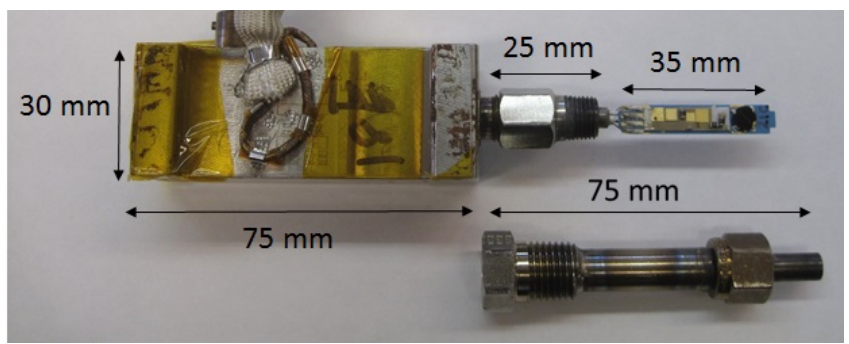

Figure 20. Packaging for pressure sensor system.

The pressure sensor system was characterized in a three-inch tube furnace. To enable pressure sensing at temperature, a custom in-house fixture was developed and is shown in Fig. 21. The packaged sensor was attached to a test fixture via Swagelok fitting so the system could be pressurized and placed in the three-inch tube furnace. A thermocouple is positioned inside the test fixture to report the temperature at the tip of the pressure sensor system, which would be located on the outer housing of the jet engine. Another thermocouple was placed on the outside of sleeve to determine the temperature closer to the electronics on the alumina substrate. The packaged pressure sensor was characterized with a spectrum analyzer at room temperature at $0,100,200,300$ and 350 psi and the results are shown in Fig. 22.

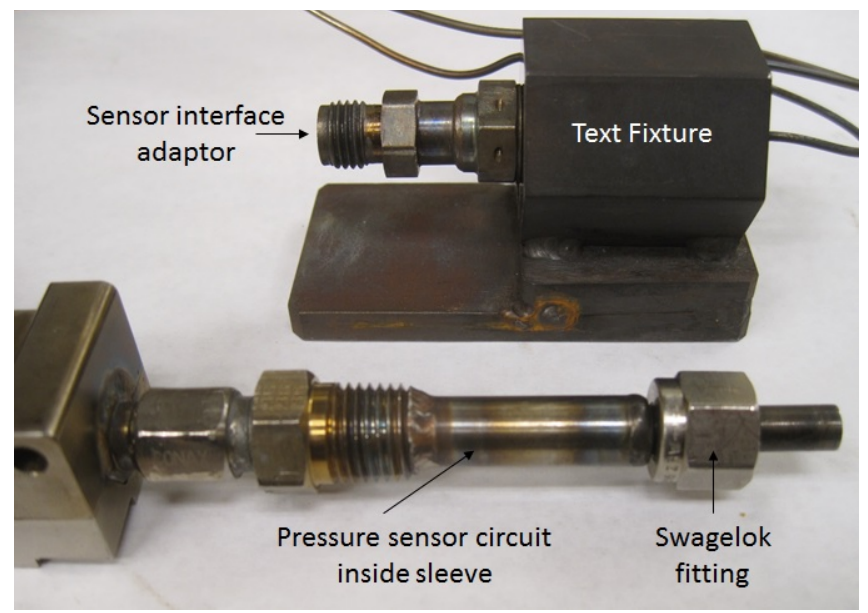

Figure 21. Pressure system characterization fixture.

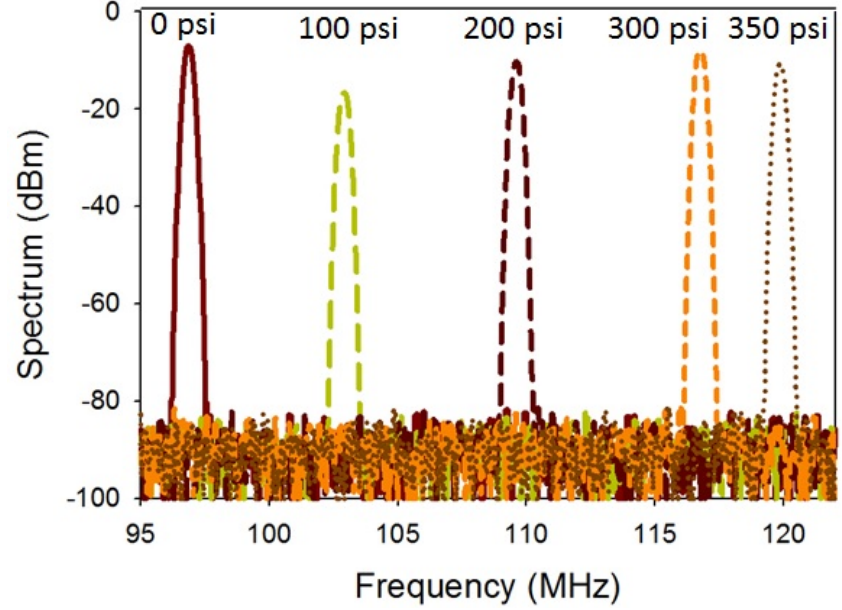

Figure 22. Packaged pressure sensor system response at 0 , 100, 200, 300 and 350 psi.

The packaged pressure sensor resonates at $96.88,102.79$, $109.54,116.77$ and $119.862 \mathrm{MHz}$, corresponding to pressures of $0,50,100,200,300$ and 350 psi, respectively. Notice that the simulated (Fig. 18) and measured responses in Fig. 22 at 0 and 100 psi are virtually identical, indicating the accuracy of the simulated design. Therefore, ADS was used to determine the capacitance of the capacitive pressure sensor at 200, 300 and 350 psi. Capacitance values of 2.83, 2.43 and $2.30 \mathrm{pF}$ were used for $\mathrm{C}_{\mathrm{T}}$ in the pressure sensor in Fig. 15, resulting in simulated responses that closely match the measured resonant responses at 109.54, 116.77 and $119.86 \mathrm{MHz}$, respectively. The result of the predicted values of capacitance as a function of resonant frequency are shown in Fig. 23. The slope of the response is $5.2 \times 10^{-3} \mathrm{pF} / \mathrm{psi}$ from 0 to $300 \mathrm{psi}$, but from 300 to $350 \mathrm{psi}$ the slope decreases to $2.6 \times 10^{-3} \mathrm{pF} / \mathrm{psi}$, suggesting that the capacitive pressure is operating out of its linear region. Thus, a second order linear regression model is better suited for the entire pressure range. The pressure as a function of frequency for the packaged pressure sensor system is shown in Fig. 24. The response is very linear over the operational pressure and frequency range.

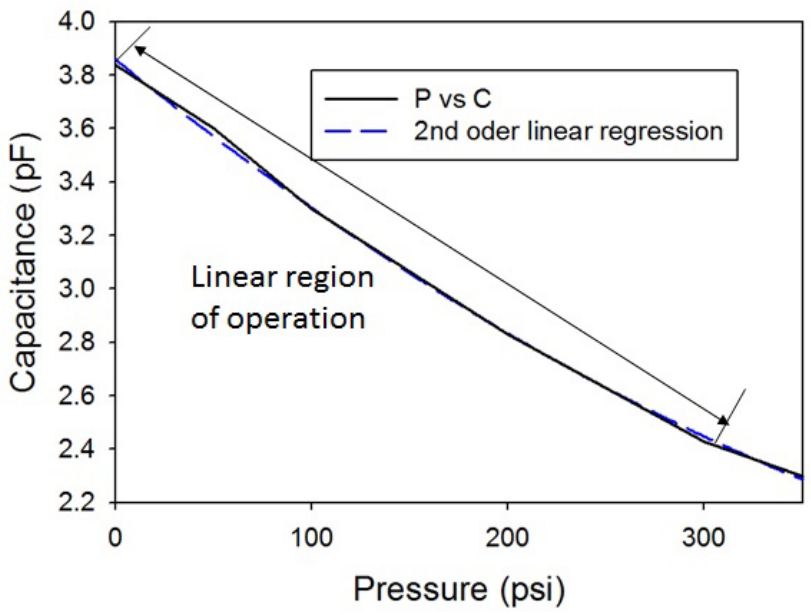

Figure 23. Capacitive pressure sensor predicted values. 


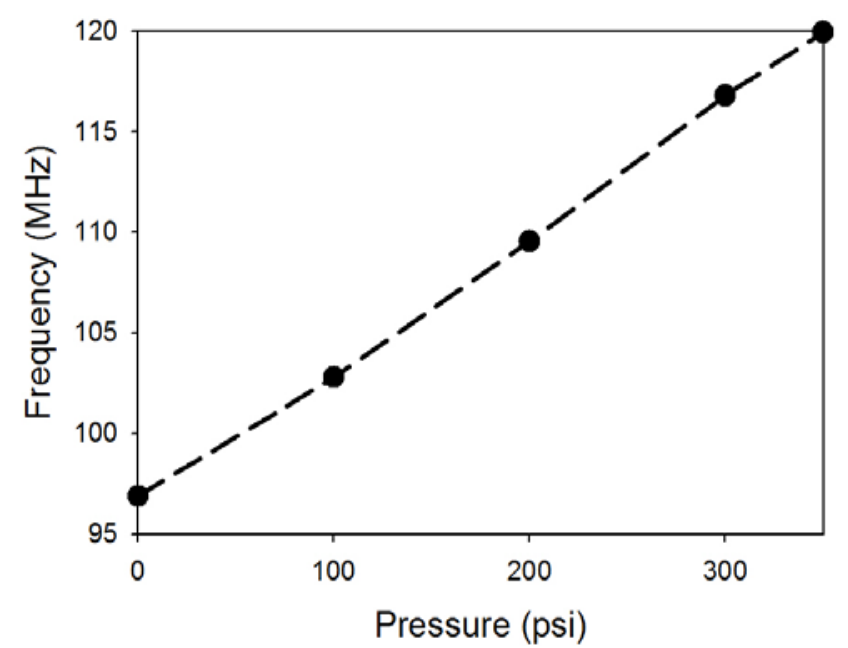

Figure 24. Frequency as a function of pressure for the sensor system.

The packaged pressure sensor was attached to the test fixture and placed in the 3 inch tube furnace as shown in Fig. 25. To emulate the test conditions on an actual jet turbofan engine, the packaged pressure sensor system was heated to over $500^{\circ} \mathrm{C}$ and the pressure was increased from 0 to over 300 psi. The frequency response of the sensor under these testing conditions is shown in Fig 26. However, the temperature recorded on the sleeve of the metal sensor packaging was approximately $400^{\circ} \mathrm{C}$, which more indicative of the temperature of the electronics. To achieve oscillation the pressure sensor system is biased with $-9 \mathrm{~V}$ on the gate, $8 \mathrm{~V}$ on the drain and a drain current of $100 \mathrm{~mA}$. The pressure sensor system at $540^{\circ} \mathrm{C}$ has a frequency shift from 96.3 to 117.8 $\mathrm{MHz}$ from 0 to 320 psi, which is a $20 \%$ change in resonant frequency. This relates to a sensor system sensitivity $(\Delta \mathrm{f} / \Delta \mathrm{P} \mathrm{MHz} / \mathrm{psi})$ of $6.8 \%$. It also worth mentioning that the resonant frequency of the sensor system at room temperature and $540^{\circ} \mathrm{C}\left(\sim 400^{\circ} \mathrm{C}\right.$ at the sleeve) is nearly the same (less than $1 \%$ ), indicating that the sensor system, specifically the electronics and pressure sensor, are highly independent of temperature.

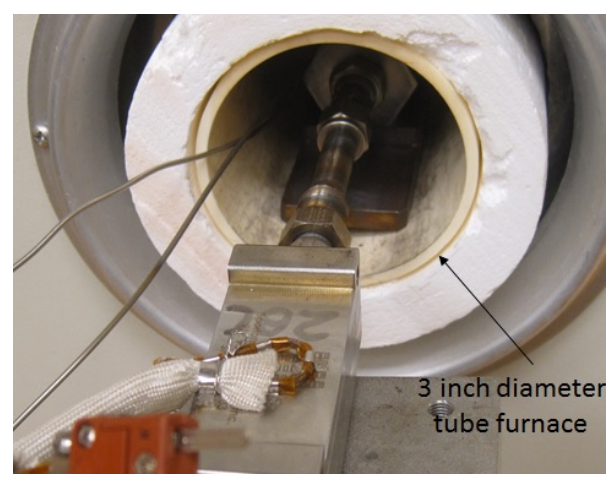

Figure 25. Test fixture and attached packaged sensor placed inside tube furnace.

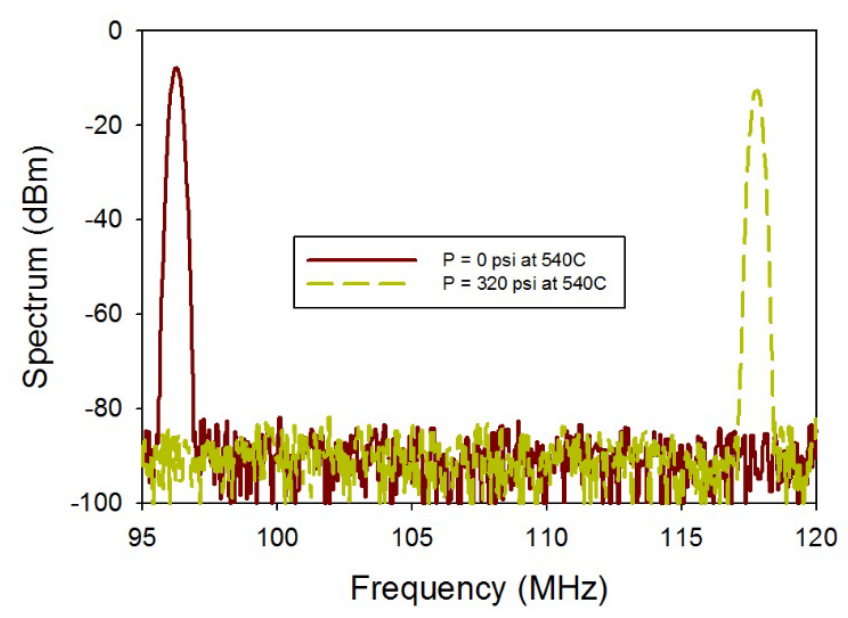

Figure 26. Frequency response of sensor system at $540^{\circ} \mathrm{C}$ for 0 and 320 psi.

Structural dynamic tests were performed to demonstrate performance relative to the expected vibration environment when affixed to a turbo fan engine. The test consists of a sine wave sweep and random vibration, with a maximum vibration of $5.3 \mathrm{G}_{\mathrm{rms}}$. The tests were performed on the $\mathrm{x}$-, $\mathrm{y}$ - and $\mathrm{z}$-axis. The packaged pressure sensor system was attached to a plate on the vibration table with a sensor interface adaptor (just as it would be if attached to the turbofan engine) on the vibration table, and is shown in Fig. 27. The resonant frequency was recorded at the beginning and end of each axis test. No change in resonant frequency was observed for the three axes. The sensor was again measured at temperature and pressure to verify it was still operating properly, and the frequency response is shown in Fig 28.

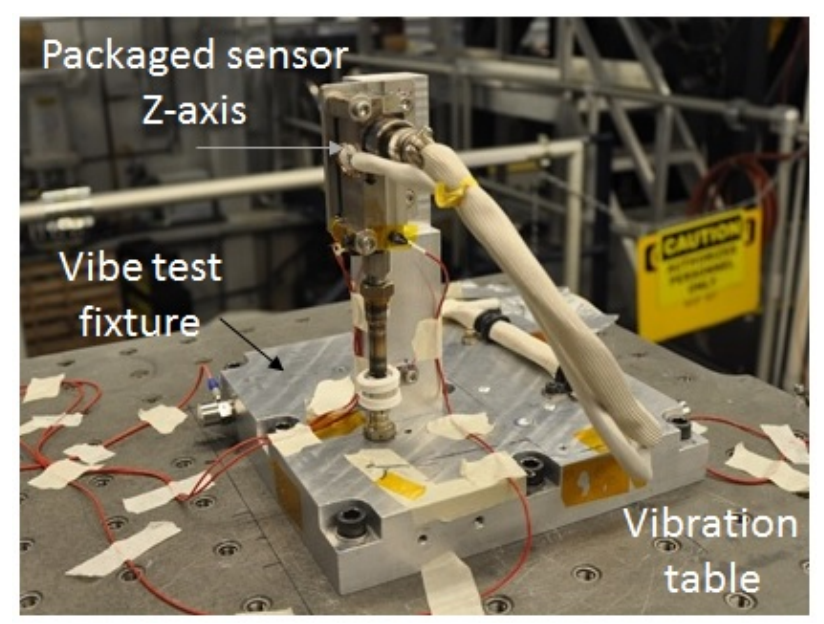

Figure 27. Vibration test setup. 


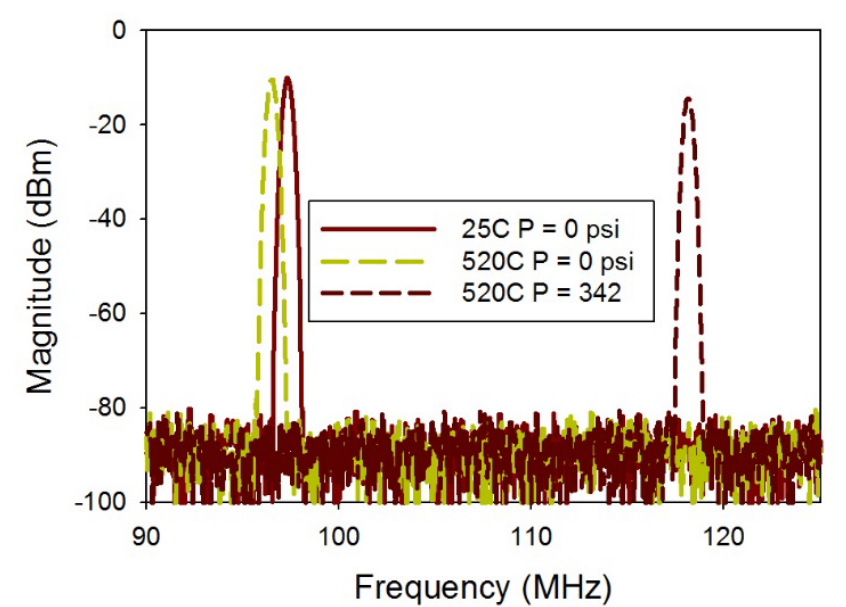

Figure 28. Sensor system operational verification after vibration testing.

\section{CONCLUSION}

A packaged pressure sensor system suitable for jet turbofan engine health monitoring has been developed. The sensor system has been characterized under relevant environmental conditions of pressure, temperature and vibration. The MEMS capacitive pressure sensor exhibited a linear response from 0 to 300 psi with a slope of $5.2 \mathrm{x}$ $10^{-3} \mathrm{pF} / \mathrm{psi}$. However, from 300 to $350 \mathrm{psi}$ the slope decreases to $2.6 \times 10^{-3} \mathrm{pF} / \mathrm{psi}$, suggesting that the capacitive pressure is operating out of its linear region. The Packaged sensor system shows negligible change in frequency response at 25 and 540 ${ }^{\circ} \mathrm{C}\left(\sim 400^{\circ} \mathrm{C}\right.$ at the sleeve) over the pressure range of 0 to 320 psi indicating that the system is not temperature dependent. The packaged system has a $20 \%$ change in resonate frequency from 97 to $117 \mathrm{MHz}$ over the pressure range of 0 to $320 \mathrm{psi}$ and the sensing system has a sensitivity of $6.8 \%$ over the operational pressure and frequency range. The packaged system can be installed via borescope plug adaptor fitted to a borescope port exposed to the gas path of a turbofan engine so it can monitor the health of jet aircraft engines.

\section{ACKNOWLEDGMENT}

The authors wish to acknowledge the assistance and support of Elizabeth A. McQuaid for the fabrication of circuits and Nicholas C. Varaljay for the high temperature/pressure chamber assembly. The support from the Aeronautics Research Mission Directorate and the Convergent Aeronautics Solutions Project is acknowledged.

\section{REFERENCES}

[1] B. W. Ohme, M. R. Larson, J. Riekels, S. Schlesinger, K. Vignarajah, and E. M. Nance, "Progress update on honeywell's deep trek high temperature electronics project," in Proceedings of the High Temperature Electronics Conference (HiTEC), (Santa Fe), p. 9, IMAPS, may 2006.

[2] E. Pennewitz, M. Schilling, T. Kruspe, S. Jung and A. Ruehs, "Acitve Cooling of Downjole Instrumentation for Drilling in Deep Geothermal Reservoirs” IEEE International Instrumentation and Measurement Technology Conference, Graz, Austria, may 13 -16, 2012. Pages 600 - 603. DOI: 10.1109/I2MTC.2012.6229454.

[3] J. Watson and G. Castro, "High-Temperature Electronics Pose Design and Reliability Challenges” Analog Dialogue, Volume 46, April, 2012.

[4] R. Johnson, J. Evans, P. Jacobson, J. Thompson and M. Christopher, "The Changing Automotive Environment: High Temperature Electronics", IEEE Transaction on Electronics Packaging Manufacturing, Volume 27, Number 3, July, 2004. Page(s): 164- 176. Digital Object Identifier: 10.1109/TEPM.2004.843109.

[5] G. W. Hunter, "A Concept of Operations for an Integrated Vehicle Health Assurance System”, NASA/TM-2013-217825, March 2013.

[6] R. D. Meredith, J. D. Wrbanek, G. C. Fralick, L. C. Greer III, G. W. Hunter, L. Chen, "Design and operation of a fast, thinfilm thermocouple probe on a turbine engine”, AIAA Joint Propulsion Conference, Cleveland, Ohio, July 28 - 30, 2014.

[7] M. R. Woike, J. W. Roeder, C. E. Hughes, and T. J. Bencic, "Testing of a Microwave Blade Tip Clearance Sensor at the NASA Glenn Research Center", AIAA Aerospace Science Meeting, Orlando, FL, January 5 - 8, 2009.

[8] M. C. Scardelletti, G. E. Ponchak, K. Harsh, J.A. Mackey, R.D. Meredith, C.A. Zorman, and G.W. Hunter, "Wireless Capacitive Pressure Sensor Operating up to $400^{\circ} \mathrm{C}$ from 0 to 100 psi Utilizing Power Scavenging", 2014 IEEE Topical Conference on Wireless Sensors and Sensor Networks, Newport Beach CA, January 19-22, 2014.

[9] R. Herrick, K. Baines, M. Bullock, G. Chin, B. Grimm, W. Kiefer, S. Mackwell, K. McGouldrick, B. Sharpton, S. Smerkar and C. Tsang, "Goals, Objectives and Investigations for Venus Exploration” Venus Exploration Analysis Group (VEXAG), 2014.

[10] L. An, Y. Wang, L. Bharaadwai, Y. Fan, L. Zhang, D. Jiang, Y. Sohn, V. Desai, J. Kapat and L. Chow, Silicoaluminum carbonitride with anomalously high resistance to oxidation and hot corrosion,” Adv. Eng. Mater., vol. 6, no. 5, pp. 337-340, 2004.

[11] Y. Wang, Y. Fan, L. Zhang, W. Zhang, and L. An, "Polymerderived SiAlCN ceramics resist to oxidation at 1400 oC," Scripta Mater., vol. 55, pp. 295-297, 2006.

[12] Y. Wang, W. Fei, Y. Fan, L. Zhang, W. Zhang, and L. An, “A silicoaluminum carbonitride ceramic resist oxidation/corrosion in water vapour,” J. Mater. Res., vol. 21, no. 7, pp. 1625-1628, 2006.

[13] X. Ren, S. Ebadi, H. Cheng, Y. Chen, L. An, and X. Gong, "Wireless resonate frequency detection of SiCN ceramic resonator for sensor applaicions," IEEE Antennas and Propagation Symp.”, Pokane, Washington, July 3 - 8, 2011, pp. $1856-1859$.

[14] N. Y. Kozlovski, D. R. Gallagher, D. C. Malocha and E. Hague, "Design of Mini-Modular Oscillators using RF and Microwave design Techniques,” IEEE Interanational Frequecny Control Symposium and Exposition, Miami, FL, June 4 - 7, 2006, pp: $351-357$. 